\title{
Colgate partners with the author of 'Aliens love Underpants' to launch Two Minute Tales
}

\author{
Beloved children's author writes brand new series called Two Minute Tales \\ to get kids excited about brushing their teeth!
}

Encouraging children to brush their teeth from a young age can be a challenge for any parent. To help put an end to the daily tantrums, foot stomping and bedtime tears, Colgate has transformed the tooth brushing experience into a fun, exciting, bonding experience for all the family with the new Colgate Two Minute Tales.

Claire Freedman is a respected children's author whose books, including Aliens Love Underpants and Dinosaurs Love Underpants, are known and loved by children across the world. Colgate has partnered with Claire to create 40 captivating two minute tales bound to delight and entertain little ones. Claire's stories are tailored to captivate children for two minutes, ensuring they brush their teeth for the recommended time to help keep teeth healthy.

Claire Freedman comments, 'I'm very excited to be partnering with Colgate on such a worthwhile campaign - encouraging children to brush their teeth whilst engaging them with listening to stories. I believe it's so important to share that special reading time with children. I hope that Two Minute Tales will make tooth brushing a fun experience - for parents and children alike.'

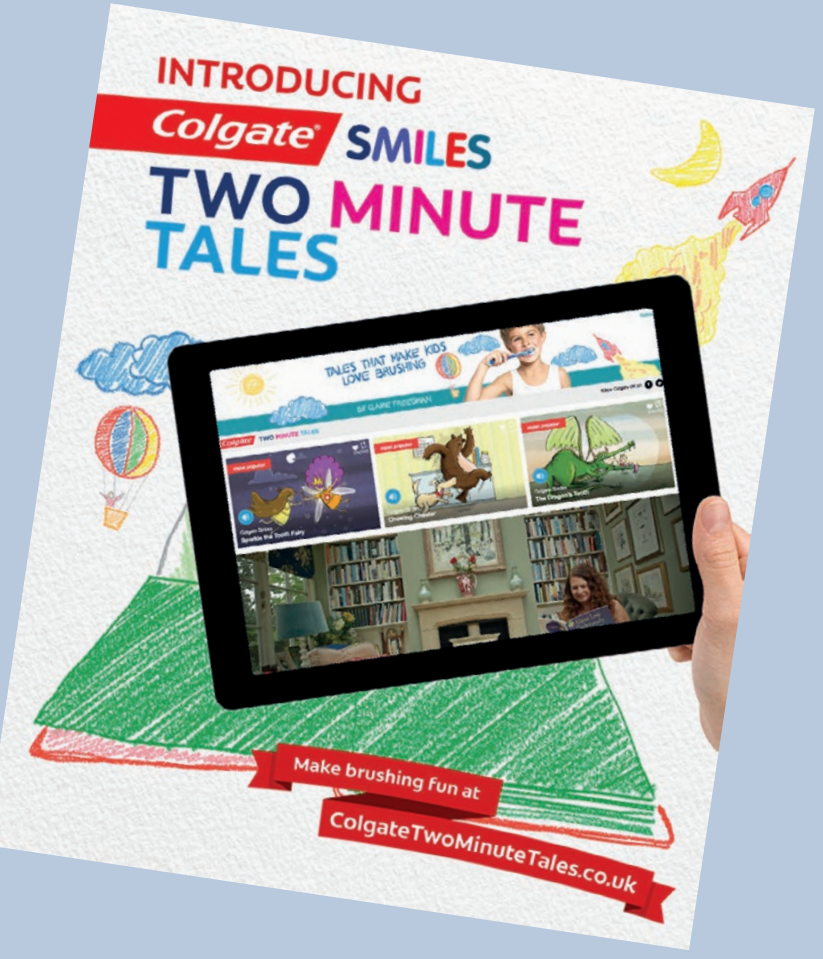

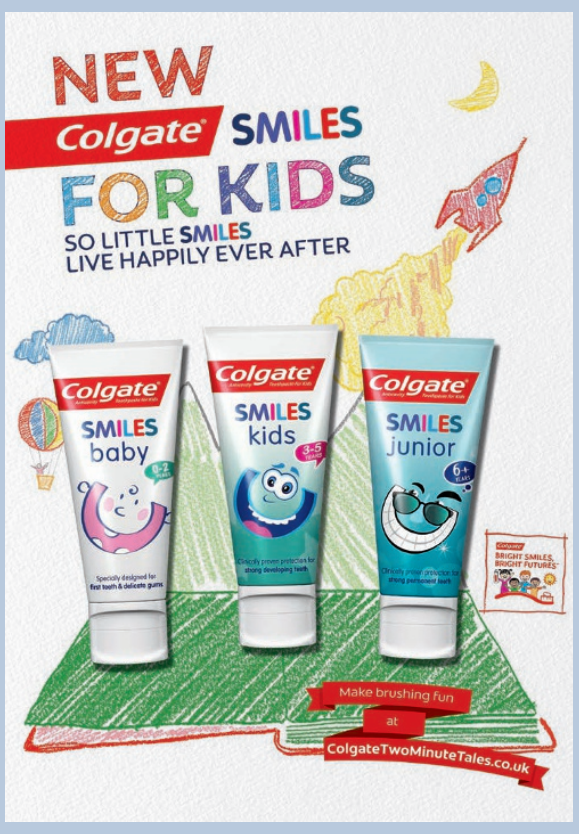

The mild flavours and convenient packaging with cute characters, paired with the Two Minute Tales is the perfect recipe to turn two minutes of brushing into two minutes of fun.

The 40 tales written by Claire will be released on www.ColgateTwoMinuteTales.co.uk between September and December 2016.

Ask your patients to visit www.ColgateTwoMinuteTales.co.uk to discover the tales. They just need to get their story telling voice ready, or they can listen to them on a tablet, phone or desktop. The stories will turn two minutes of brushing into two minutes of fun for your child patients!

1. 'Delivering better oral health. An evidence-based toolkit for prevention'. 3rd edition, Public Health England, June 2014. prevention':

Colgate has also released a new range of toothpastes specifically designed to make hing a fun experience and offer age appropriate fluoride levels as recommended

- Colgate Smiles Baby Anticavity Toothpaste 0-2 Years (1000 ppm F)

- Colgate Smiles Kids Anticavity Toothpaste 3-5 Years (1450 ppm F)

- Colgate Smiles Junior Anticavity Toothpaste 6+ Years (1450 ppm F)

\section{NEW Colgate SMILES TWO MINUTE TALES}

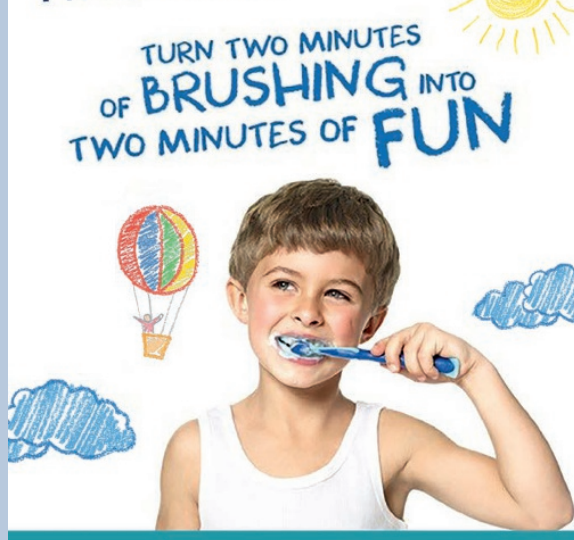

Learn how at ColgateTwoMinuteTales.co.uk 